\title{
"بين الله والإنسان في القرآن: دراسة دلالية لنظرة القرآن إلى العالم" \\ للمؤلف: توشيهكو إيزوتسو*
}

\section{ع عيسى علي العاكوب}

المؤلف كان أستاذا في معهد الدراسات الثقافية واللغوية، جامعة كيو Keio University في العاصمة اليابانية طوكيو. وكان لامعا في الدراسات المهتمة بالقرآن والثقافة الإسلامية. ويلاحظ أن عددا من الدارسين للإسالام والثقافة الإسهلامية من الغربيين يرجعون إلى مؤلفاته. وهو في كتابه الذي نعرف بمادته العلمية الآن The Structure of : .the Ethical Terms in the Koran

ويبدي المؤلف في هذا الكتاب اقتداراكبيرا في فهم القرآن الكريم والشعر العربي، كما تنم تأملاتهُ على إلمام كبير بتاريخ الثقافة الإسلامية منذ نشأقها الأولى إلى عصور ازدهارها وتمائها. ويستشعر قارئ كتابه رصانته الكبيرة واتزانه واحترامه الكبير لكتاب الله سبحانه وللمفهومات القرآنية.

أعـد كاتب هـذا التعريف ترجمة عربيـة لهذا الكتـاب، في طريقها إلى النشـر إن شـاء الله. أمـا الكتـاب نفسه فقد تناول المؤلف فيه تغيرَ دلالات الألفاظ العربية التي استخدمها القرآن الكريم عما كانت عليه في الجاهلية، وقصد من ذلك إلى بيان أن هذا التغير الدلالي عبر عن أمر غاية في الأهمية، وهي نظرةٌ جديدة كل

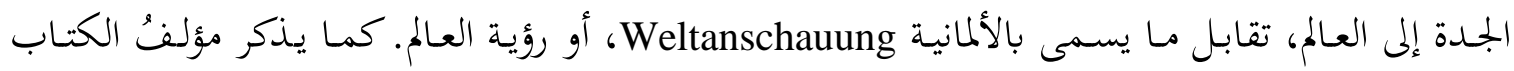
الأستاذ توشيهيكو إيزوتسو Toshihiko Izutsu في مقدمته أنه حاول الإسهام بشيء جديد في سبيل فهم أفضل لرسالة القرآن لدى أهل عصره الأول، ولدى أهل زماننا أيضا.

ويبين في الفصل الأول مـن الكتـاب "الـدرس الـلالي والقرآن" أن الشطر الرئيس مـن هذه الدراسـة مهتم حصرا تقريبا بمسألة العلاقة الشخصية بين الخالق العظيم، سبحانه والإنسان في القرآن. وذلك في دراسة دلالية للرؤية القرآنية للعالمَ. ويوضح أنه مهتم بنقطتين أساسيتين: الدرس الدلالي والقـرآن، وقـد أراد منـذ البداية أن يكون لدى القـارئ فكرة جلية تمامـا عن ارتباط المنهجية القائمة على علم الدلالة يلم

\footnotetext{
* Izutsu, Toshihiko. God and Man in the Koran: Semantics of the Koranic Weltanschauung, Tokyo: Keio Institute for Cultural and Semantic Studies, Keio University, Japan, 1964.
}

** أستاذ البلاغة والنقد ورئيس قسم اللغة العربية في جامعة قطر ialakoub@qu.edu.ga 


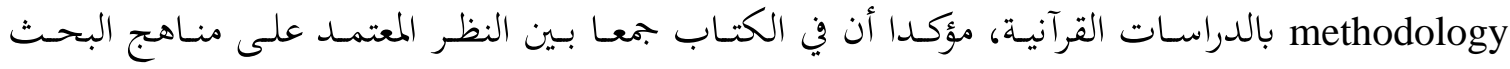

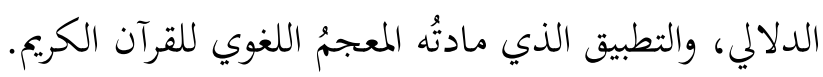

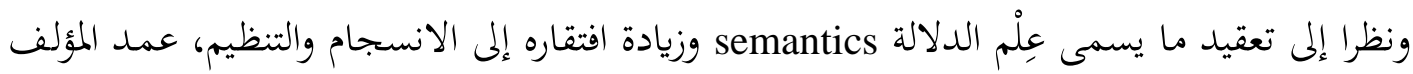

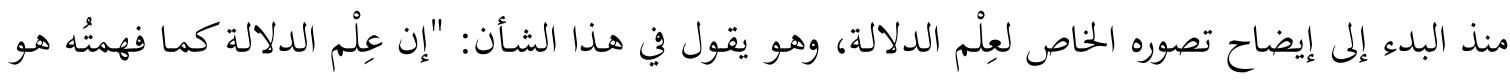
دراسةٌ تحليلة للتعابير المفتاحية Key-terms في لغةٍ من اللغات ابتغاء الوصول إلى إدراك مفهومي لرؤية العالم

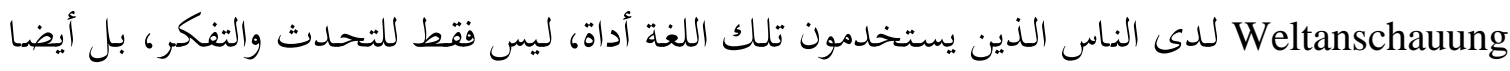

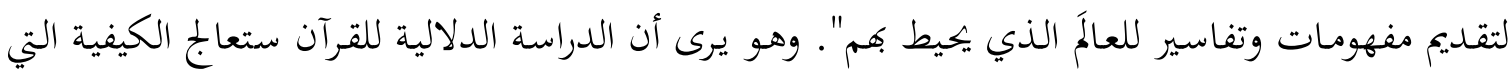

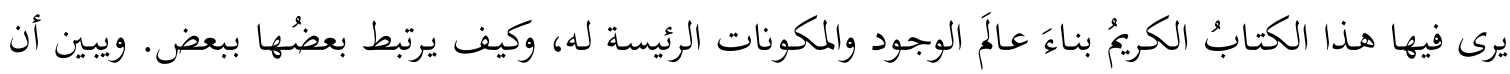

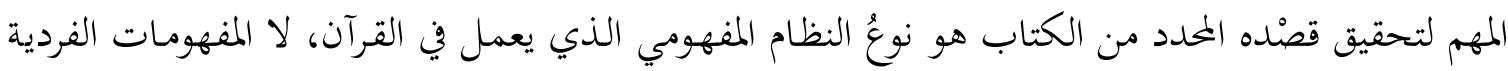

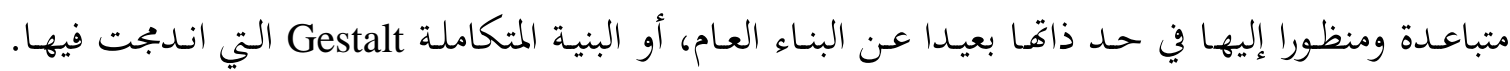

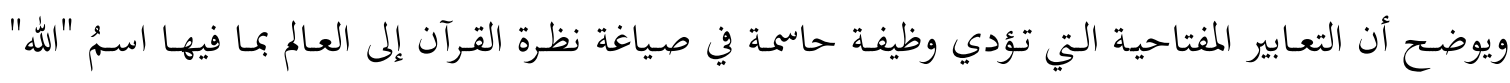

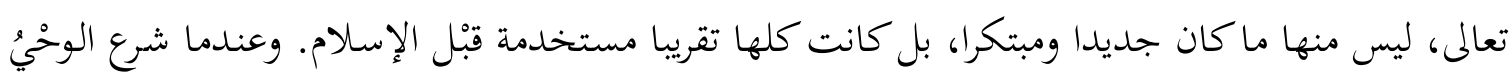

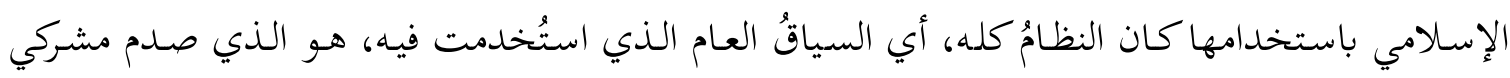
مكة بوصفه شيئا غريبا وغير مألوف وغير مقبول، تبعا لذلك.

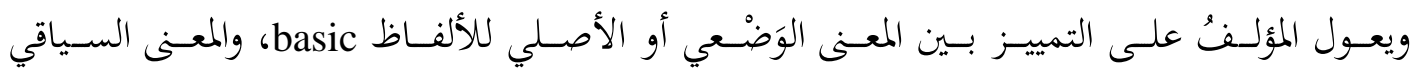

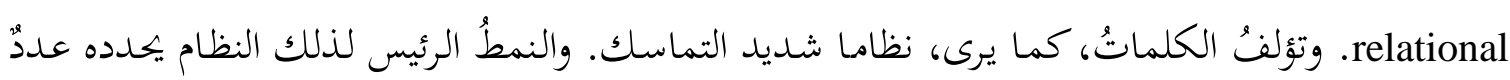

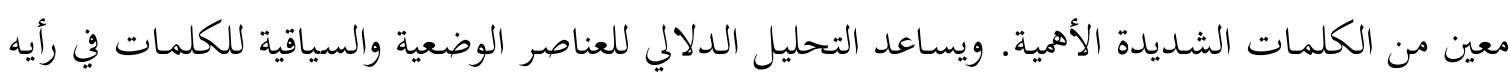

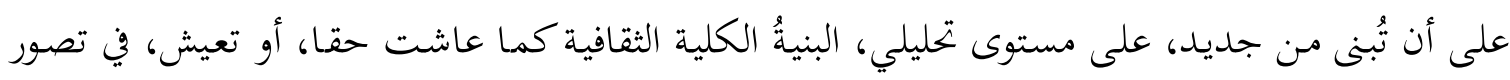

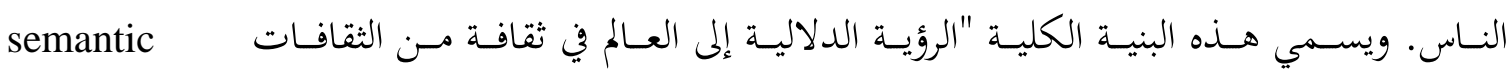

.Weltanschauung

أما ما نوعُ هذه الرؤية وكيف تُنشأ أساسا وأيةُ أسسٍ لابد منها لكي تظل تشكل فلسفيا نظرية فعالة

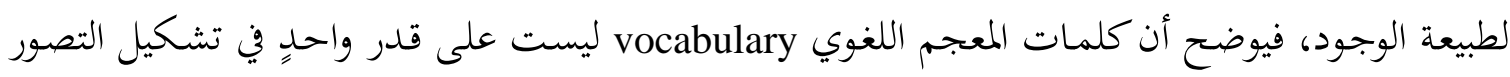

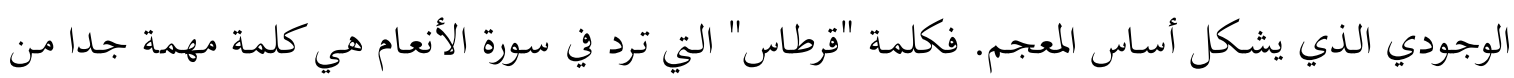

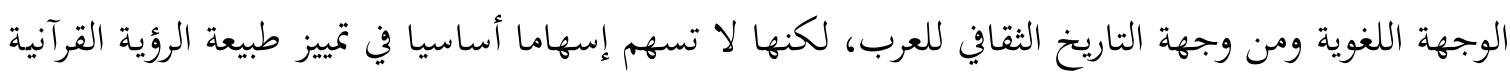

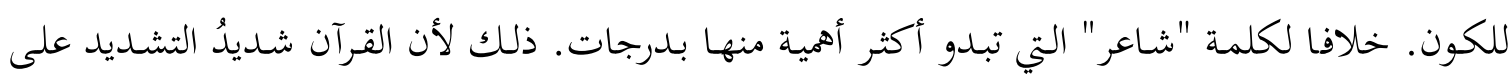

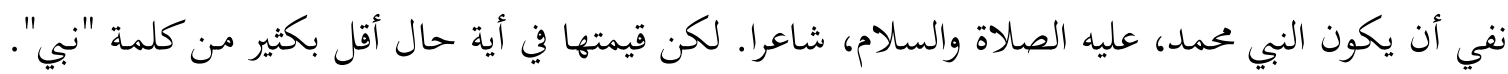

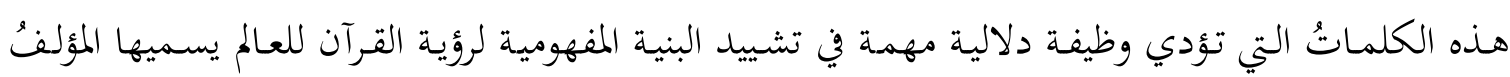

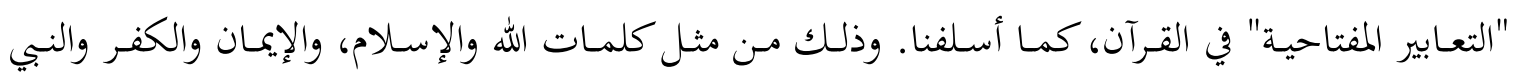


والرسول. ويوضح المؤلفُ أن أصعب جزء من مهمة الدرس الدلالي في القرآن من وجهة نظر الدلالة هو قبّلَ كل شيء عزّلُ التعابير المفتاحية لجملة المعجم القرآني. ويقوم عملُ المؤلف في الكتاب على أساس تصور واضح لديه يذهب إلى أن المعجم اللغوي لأي نص

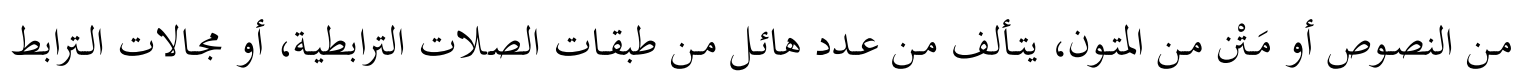

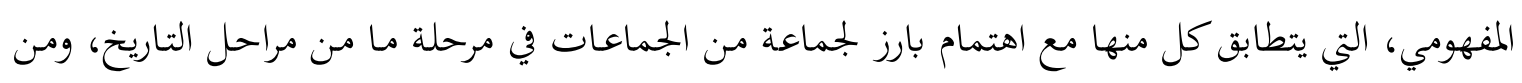

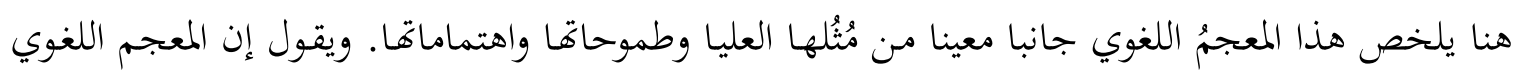

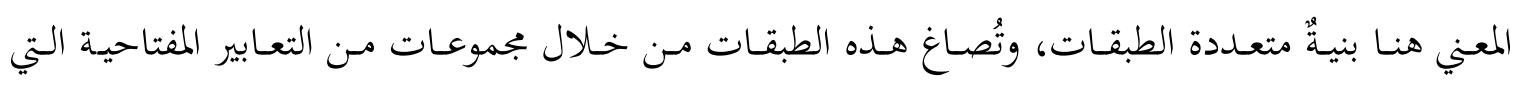

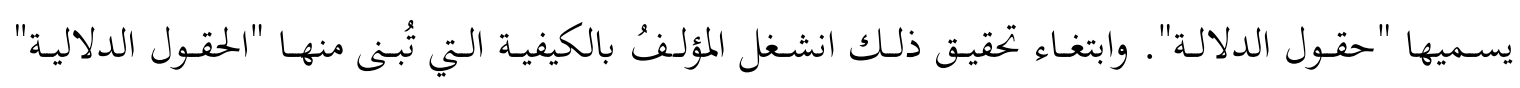

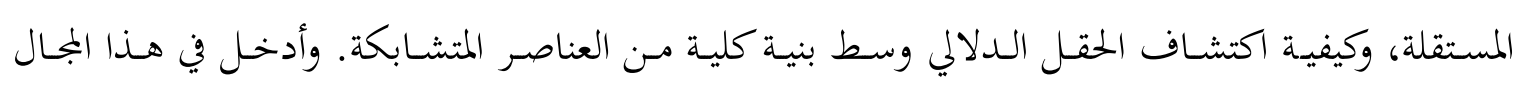

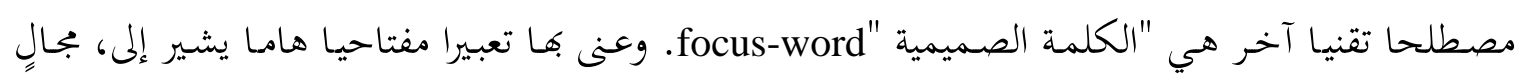

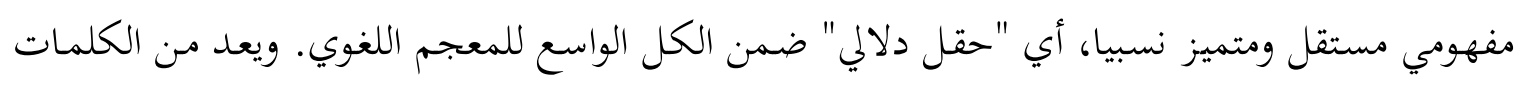

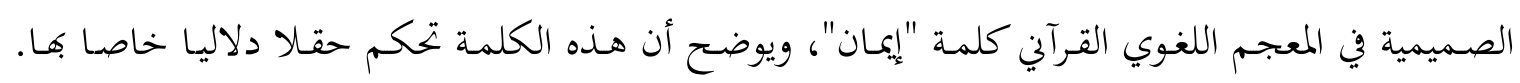

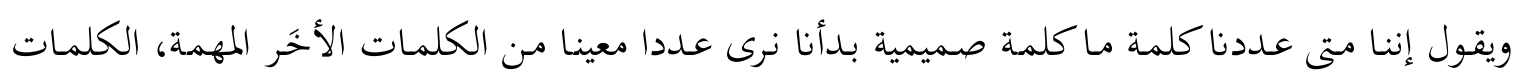

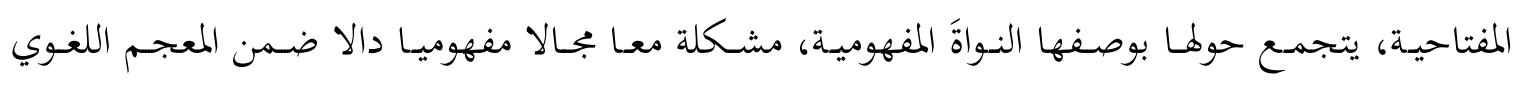
الشامل للقرآن.

ويتمتع المؤلفُ بقدرة تنظيرية عالية، تتجلى في مواقف عملية متعددة تتراءى لقارئ الكتاب. ومسن

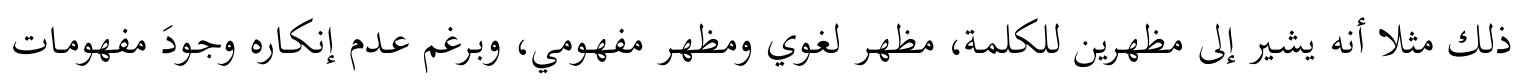

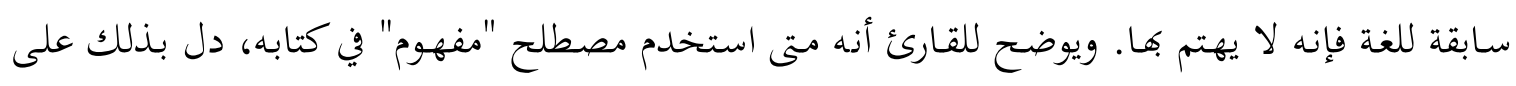

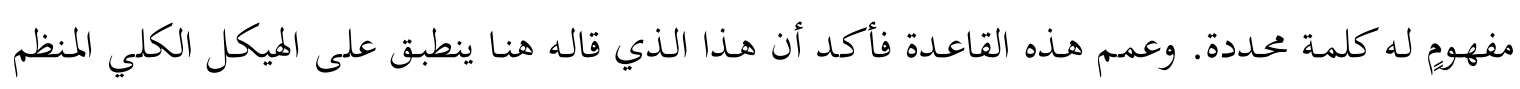

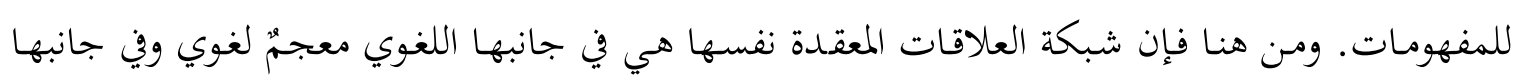

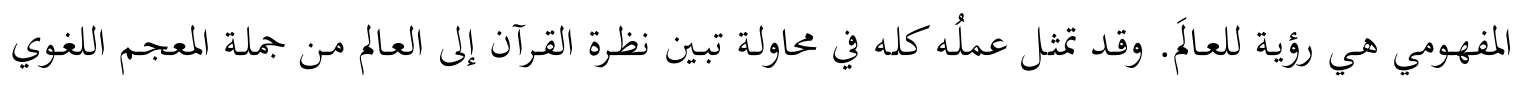

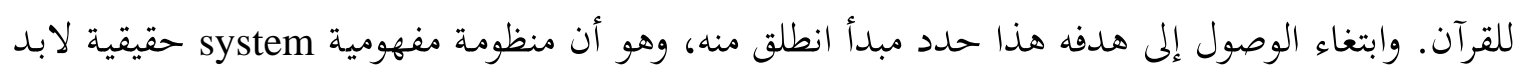

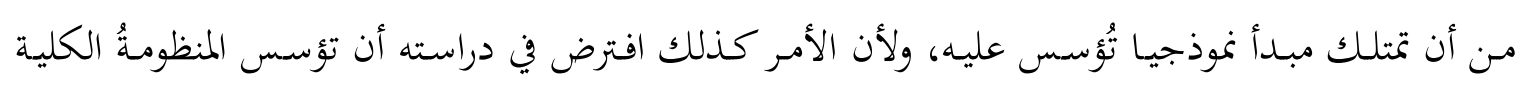

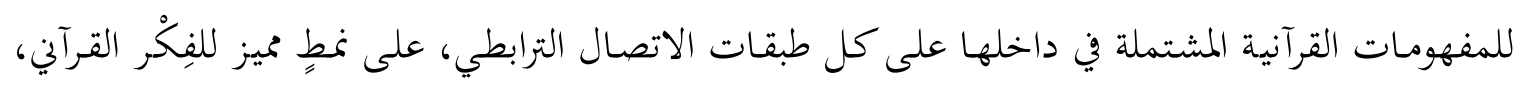

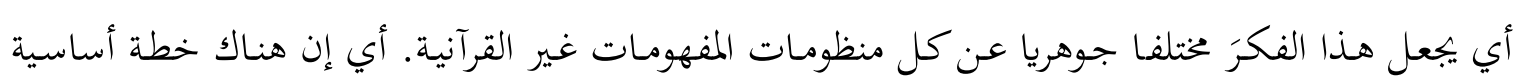

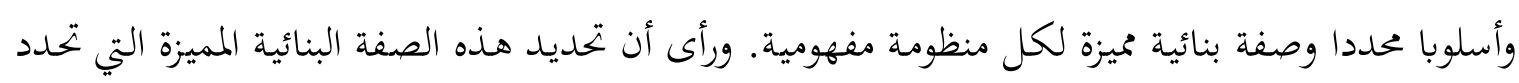

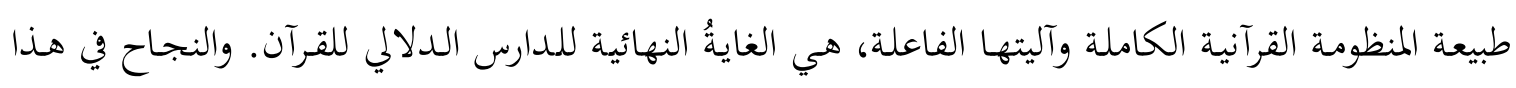

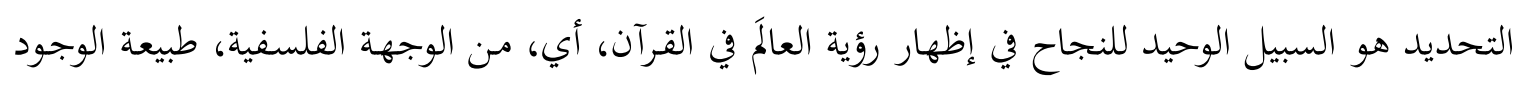


كما يراه القرآن. ويعترف بصعوبة هذه المهمة، وييين أن دراسته بجرد خطوة أولى ومتواضعة جدا في اتجاه هذا الهدف النهائي.

وقد مضى المؤلفُ في الفصول اللاحقة في تطبيق منهجيته التي حددها في الفصل الأول. فتحدث في

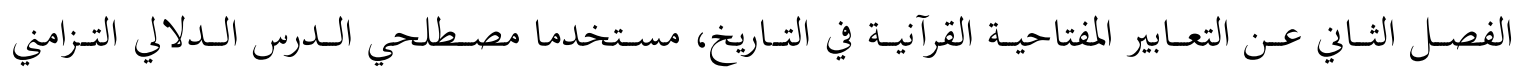

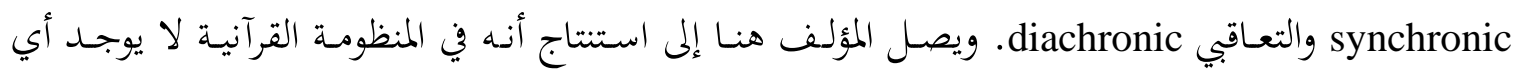

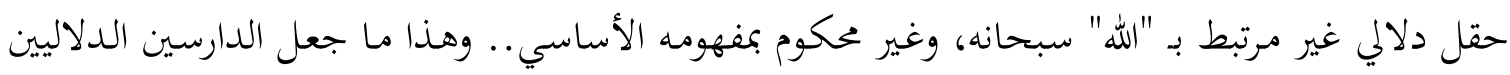

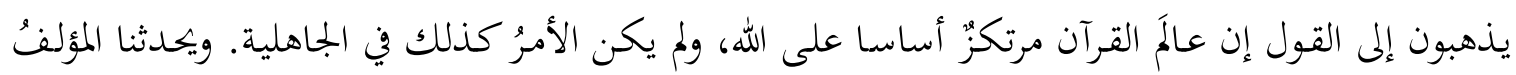

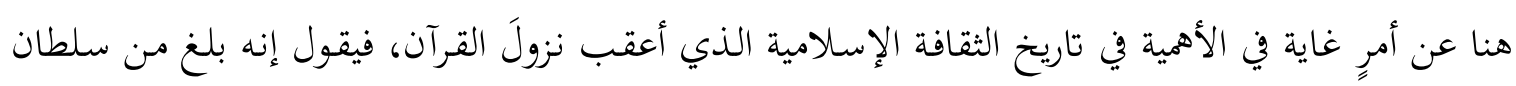

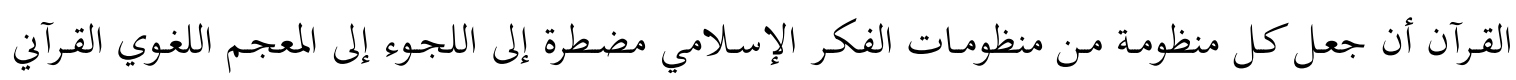

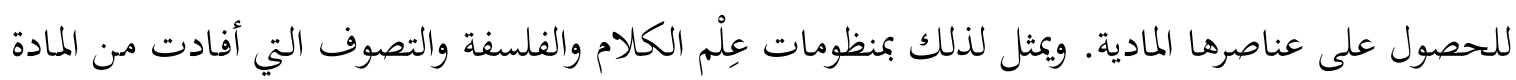
اللغوية القرآنية في تعابيرها المفتاحية والصميمية.

ويؤلف الفصلُ الثالث الموضوعَ الدقيق للكتاب، أي البنية الأساسية للرؤية القرآنية للعالم. وههنا يسعى

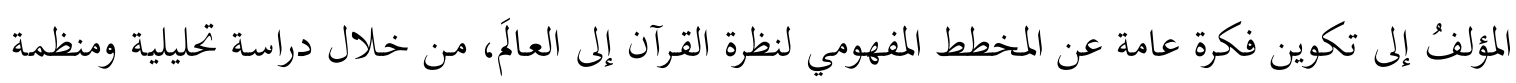

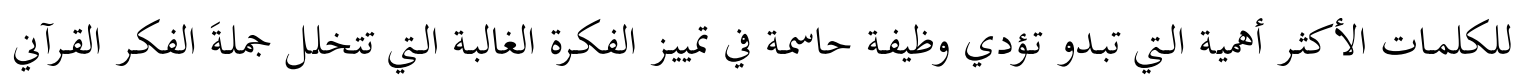

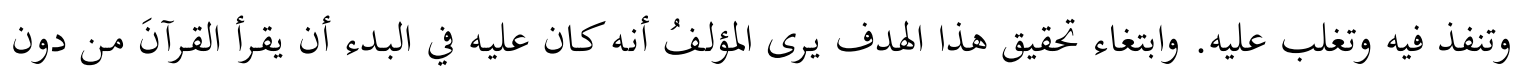

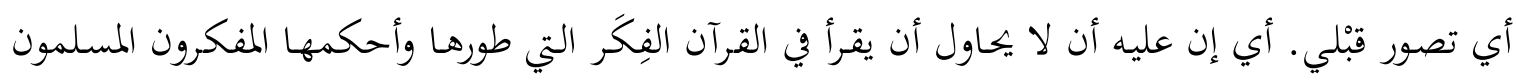

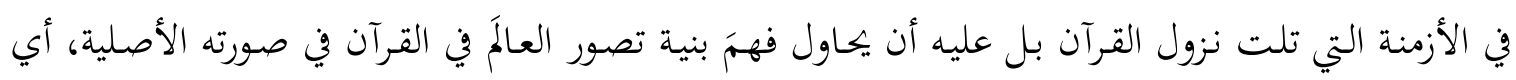

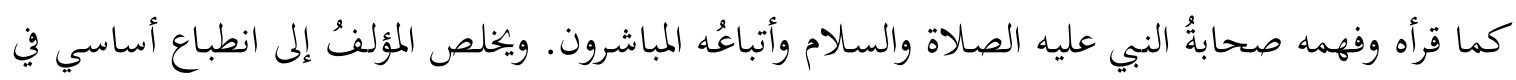

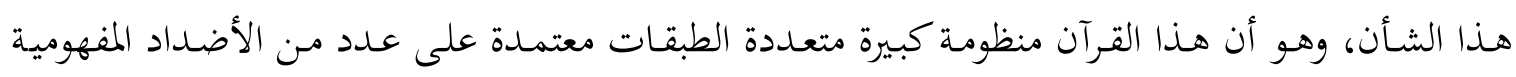

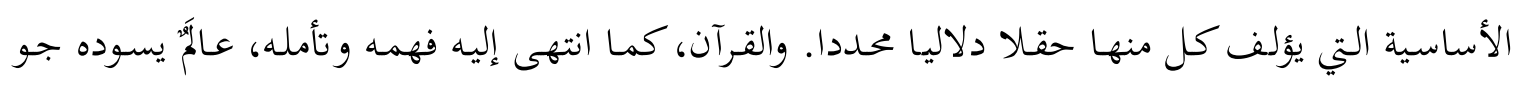

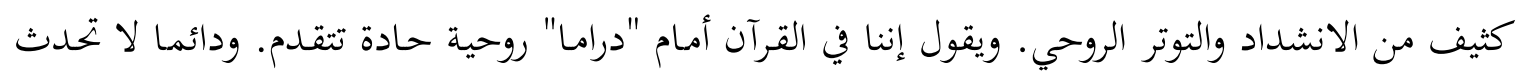

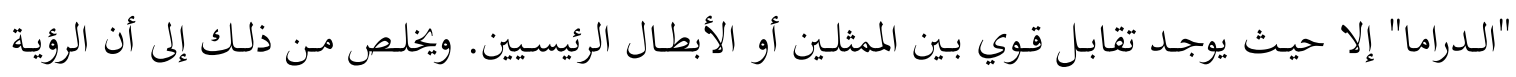

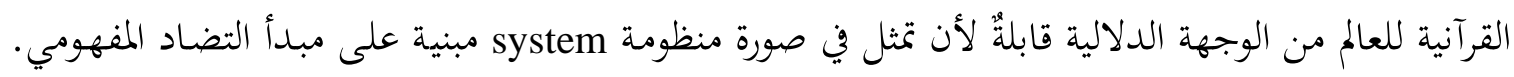

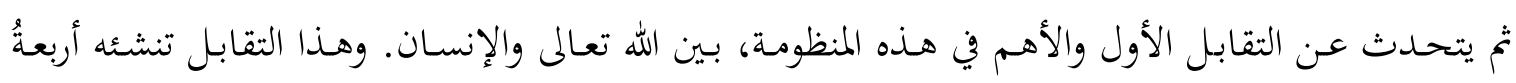

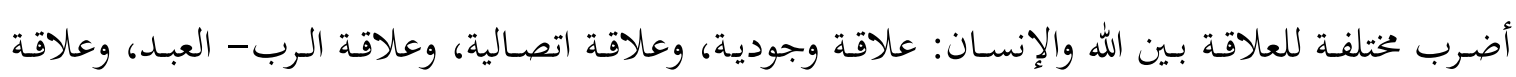
أخلاقية.

ويرى أن هذه العلاقات متى رُسخت بين الله، سبحانه، والإنسان ولدت جماعة خاصة من الرجال

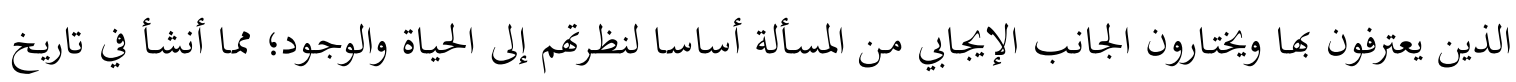

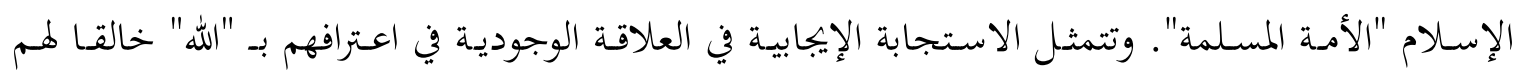


وموجدا ومعتنيا بمصيرهم. أمـا الاستجابة الإيجابية في علاقة الاتصال فتتمثل في استجابة الإنسان استجابة

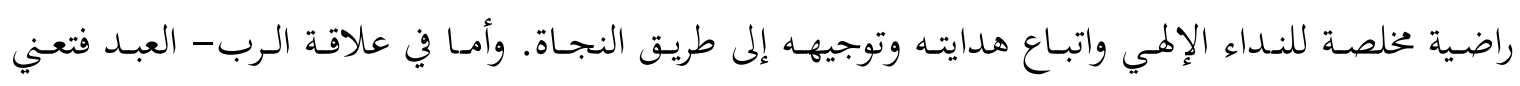

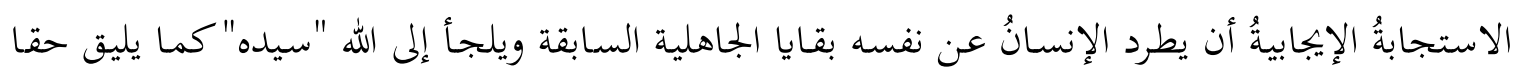

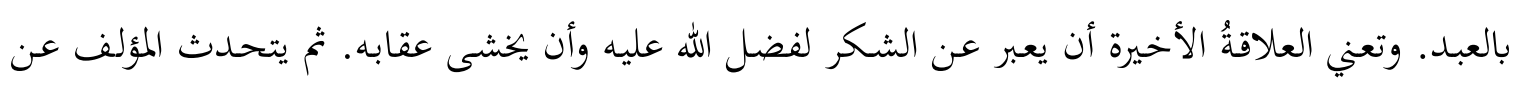

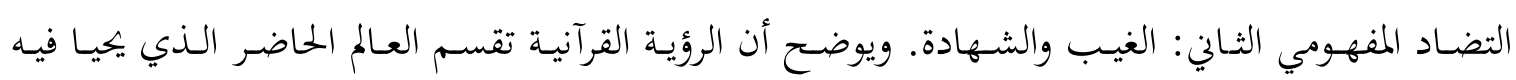
الإنسانُ إلى نصفين، عالمَ الغيب وعالَّم الشهادة.

ويخصص الفصلَ الرابع للكلمة الصميمية في المعجم اللغوي القرآي: الله. ويبين أن النظرة إلى العالَّ في

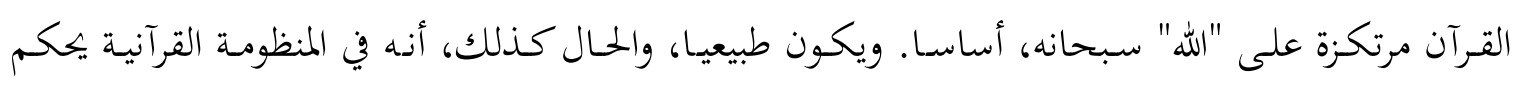

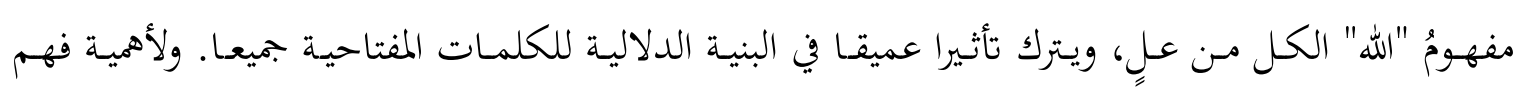

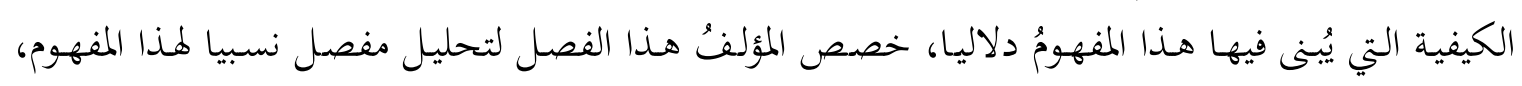
وجعل ذلك مـدخلا إلى دراسـة المسـألة الأساسية لديـه، مسـألة العلاقـة الرباعية بـين الله تعـالى والإنسـان. ويتحدث المؤلفُ هنا عن تطور المعنى "السياقي" لكلمة "الله" بين عرب الجاهلية، ويميز بين ثلاث حالات مختلفة: المفهوم الوثني لله، ومفهوم اليهود والنصارى لهذه الكلمة في العصر الجاهلي، واستخدام العرب الوثنيين

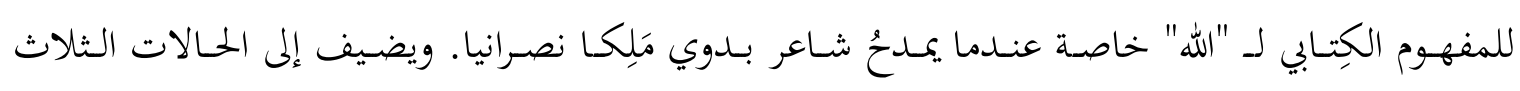

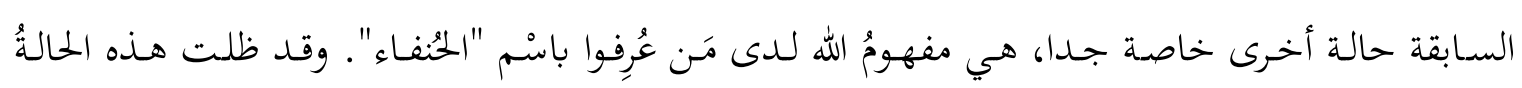

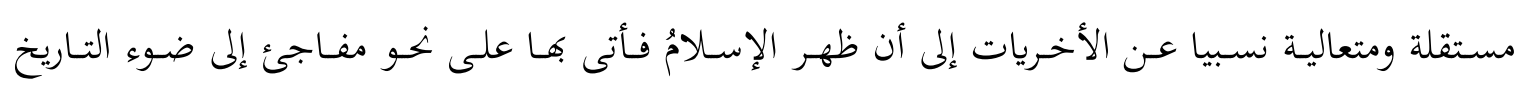
المتألق.

ثم كان الفصلُ الخنامس من الكتاب محلال لمناقشة العلاقة الوجودية بين الله والإنسان، وقد ناقش فيه

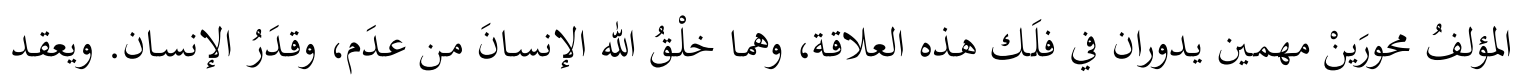

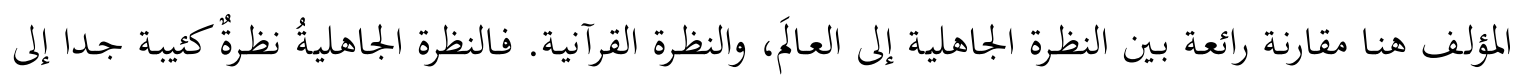
الحياة، إذ تُصورُ الحياة كلها سلسلة من الفواجع، التي لا يهكمها القانون الطبيعي للنماء والبِلى، بل الإرادة الغامضة لكائن مظلم أعمى شبه شخصي، لا منجاة من قبضته القوية. أما عالَّ القرآن فيقدم صورة مختلفة

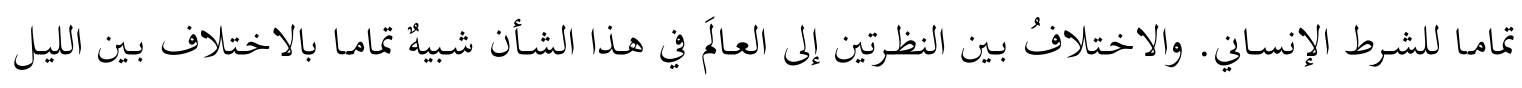

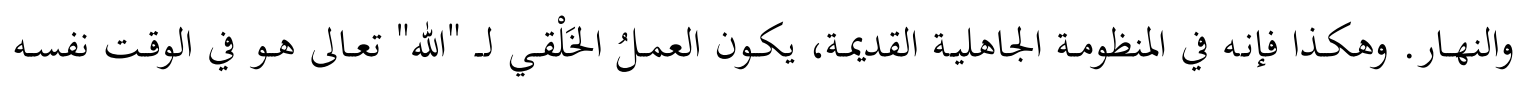
البدايةً والنهاية لتدخل الله في شؤون الإنسان، و "الله" من حيث المبدأ لا يعبأ بمَنْ أتى بهم إلى الوجود، كحال

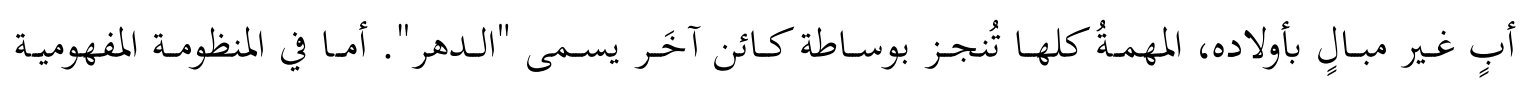

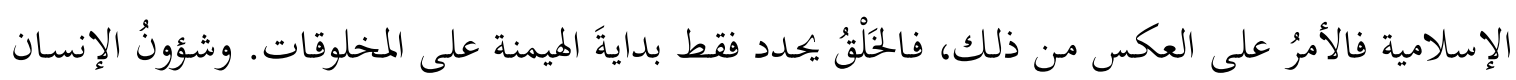
كلها، حتى أدق تفاصيل الحياة وأكثرها أهمية في الظاهر، تحت الاطلاع الصارم والمراقبة الدقيقة لحضرة "الله" 
سبحانه. والأكثرُ أهمية في هذا الشأن أن "الله" في القرآن هو "الله" ذو العَدْل الذي لا يظمل أبدا. ولا شأن للدهر، ولا لمكائده الأكثر خفاء.

وجاء الفصُلُ السادسُ مـن الكتاب ليعالج العلاقةً الثانية، الاتصالية، بين الله سبحانه والإنسان في

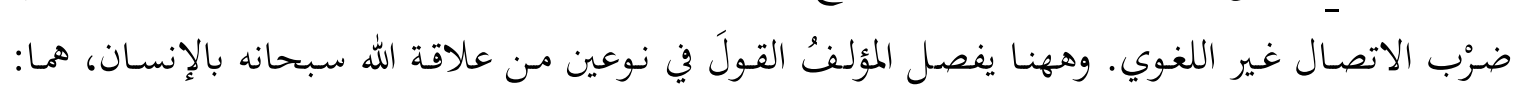

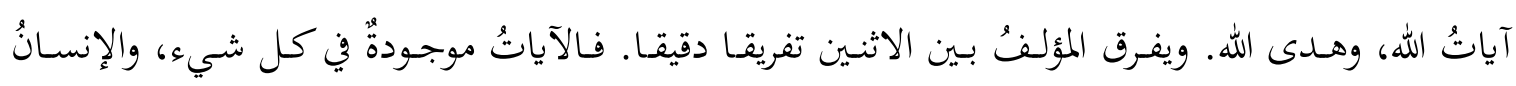

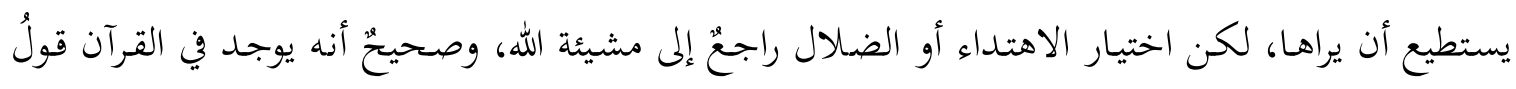

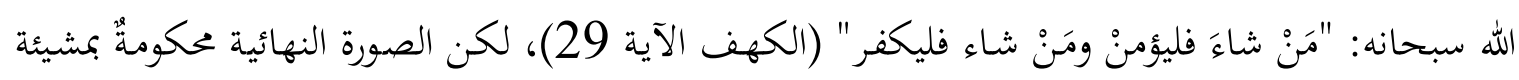

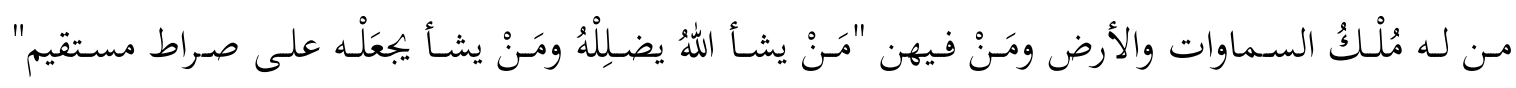

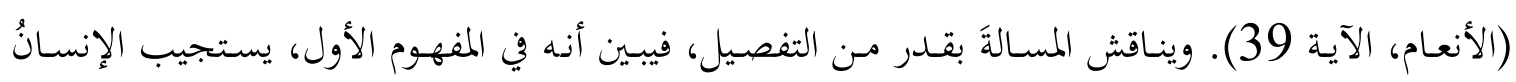

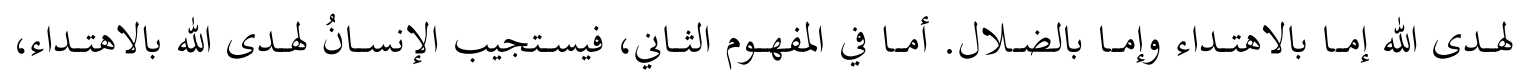

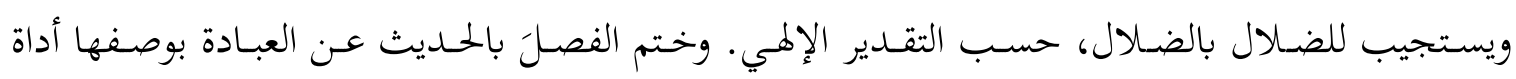
لاتصال العبد بربه.

وفي الفصل السـابع، وهـو أطولُ فصـول الكتـاب، يتحـدث المؤلفُ عـن العلاقة الاتصـالية بـين الله

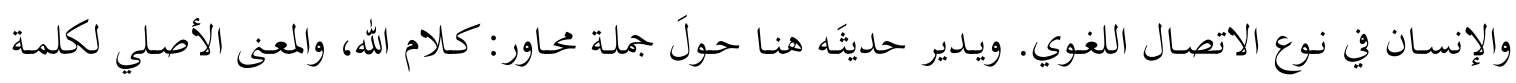

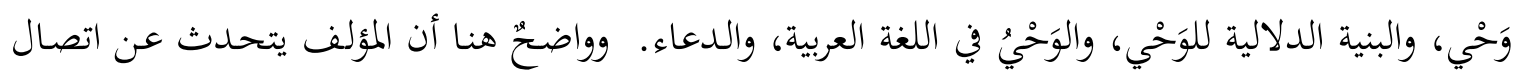

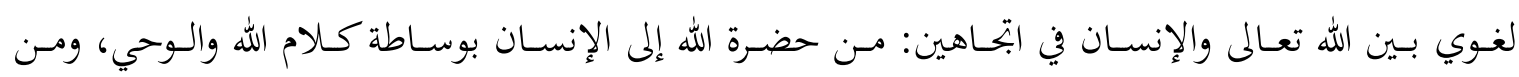
الإنسان إلى الله بوساطة الدعاء.

وييجيء الفصلُ الثامنُ ليحتضن حديث المؤلف عن الجاهلية والإسلام، وقد عالج فيه الجانب الثالث

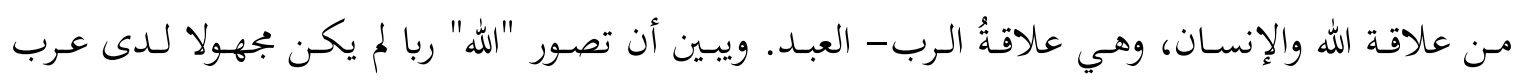

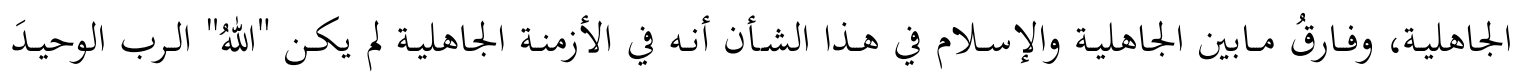

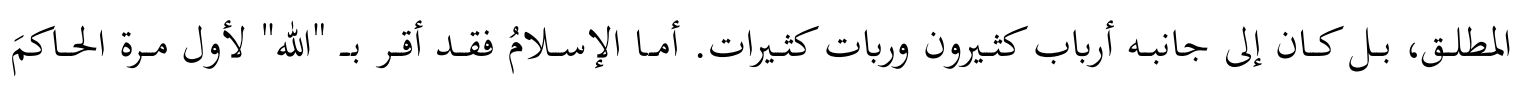

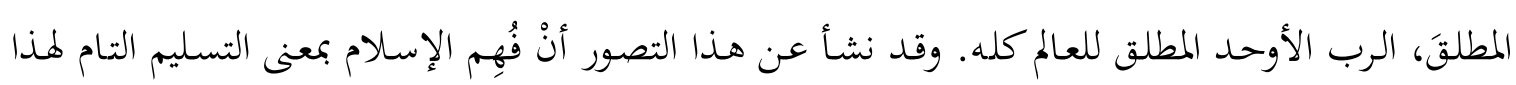

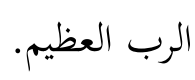

الفصلُ التاسعُ الأخيرُ يعقده المؤلفُ للحديث عن العلاقة الرابعة بين الله والإنسان: العلاقة الأخلاقية.

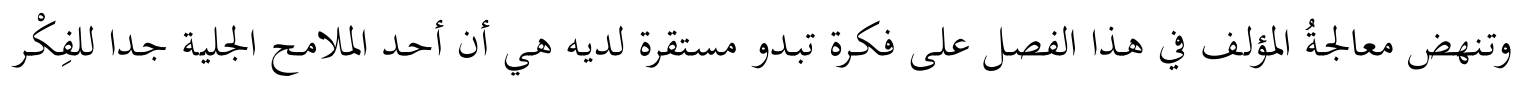

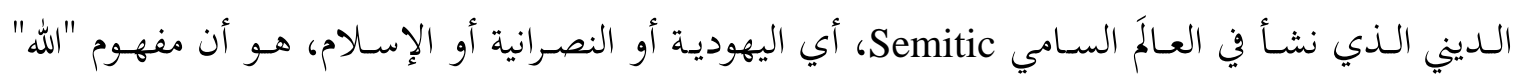

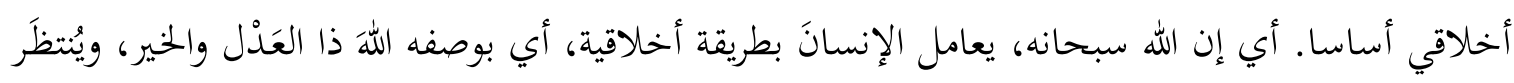

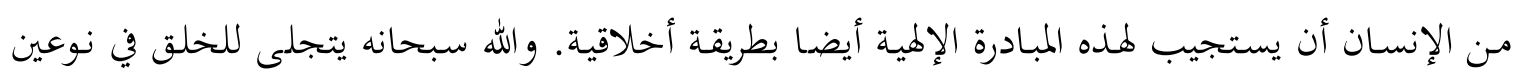


مختلفين من التجلي: اللهُ ذو الرحمة، واللهُ ذو الانتقام، أو اللهُ ذو الفضل والله ذو العَدْل. و اللهُ سبحانه يعامل

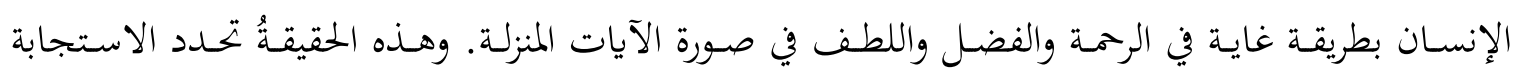

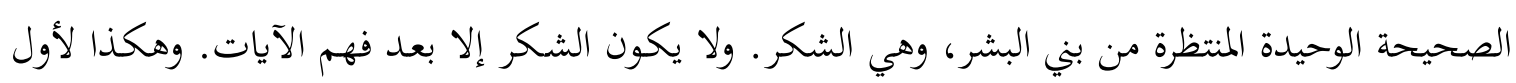

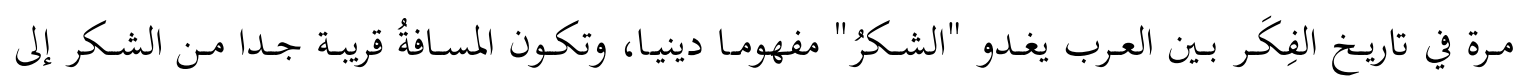

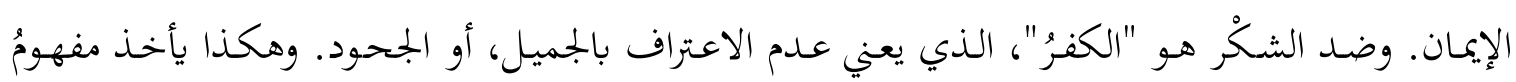

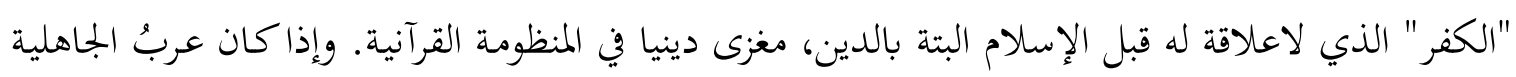

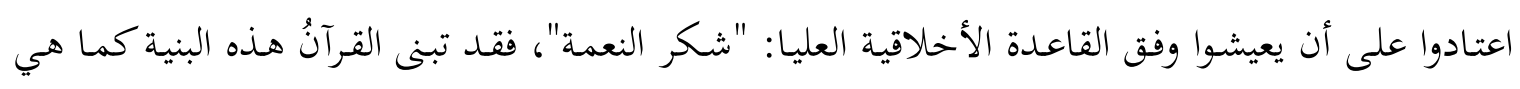

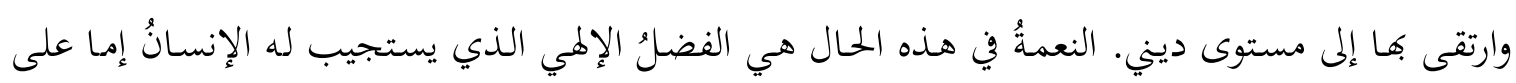

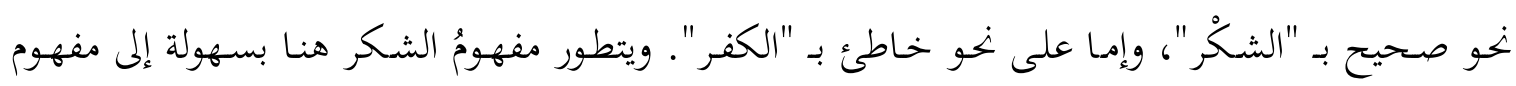

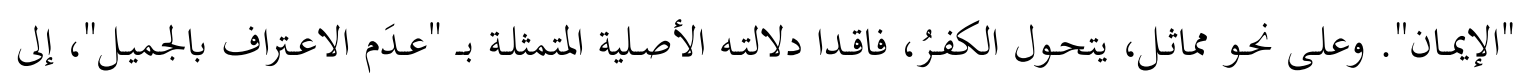

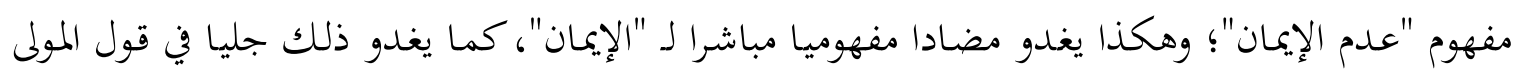

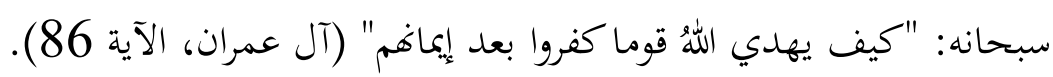

أما لمنْ يتخذون موقفَ الكفر بدلا من الشكر أو الإِيمان، لمن يرفضون الخضوع لله ولمنْ يغفلون تماما

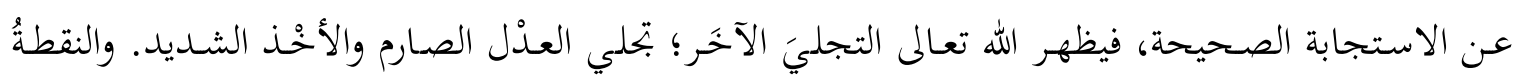

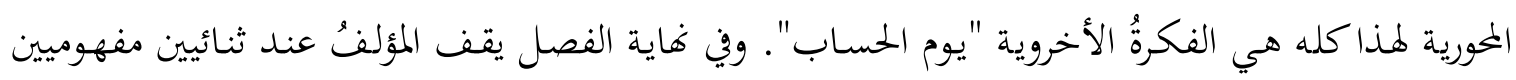

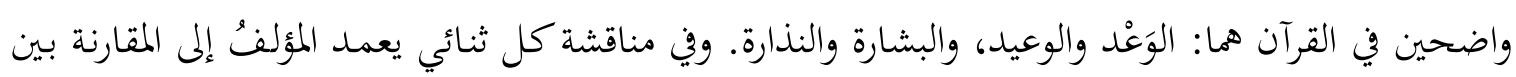
ماكان عليه الأمرُ في الجاهلية وما آل إليه في الإسلام.

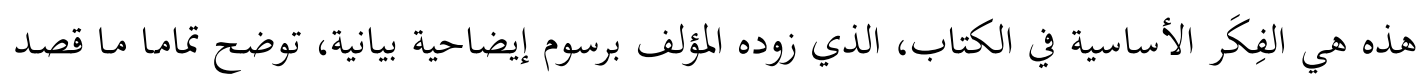

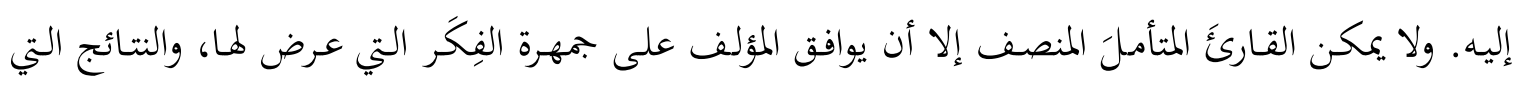

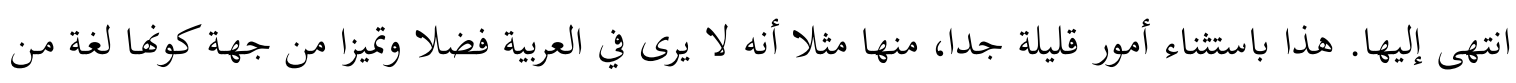

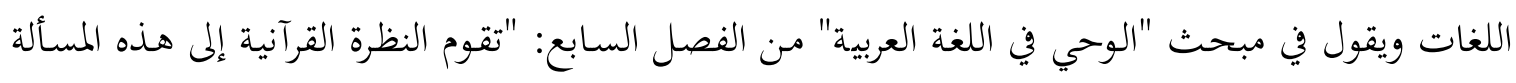

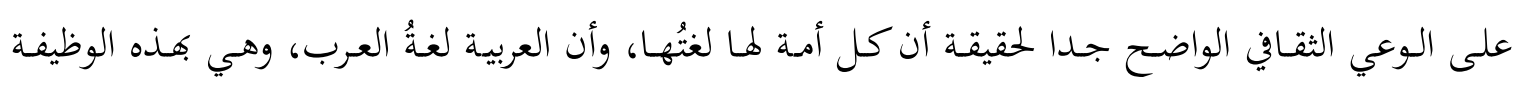

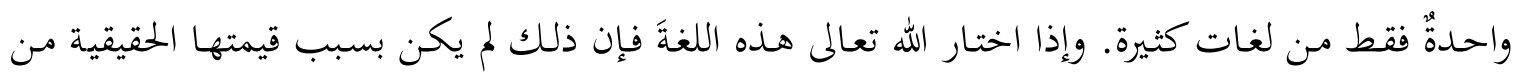

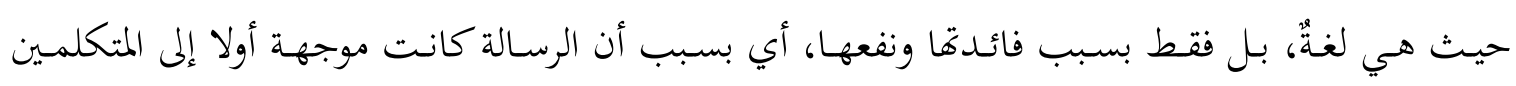

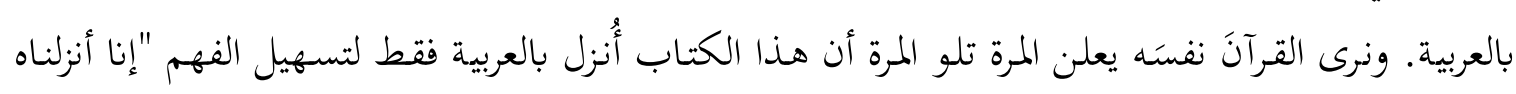

$$
\text { قرآنا عربيا لعلكم تعقلون" (يوسف، الآية 2). }
$$

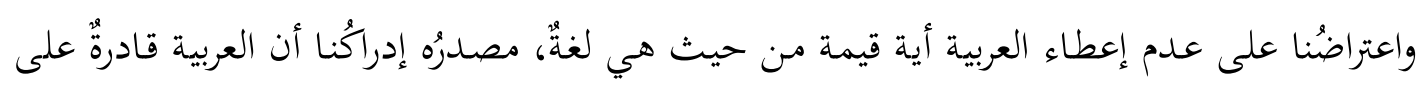

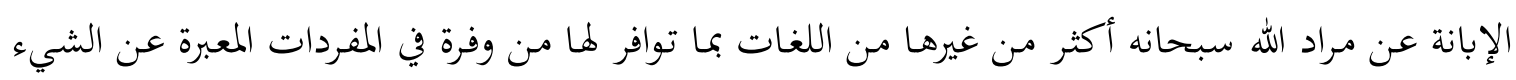

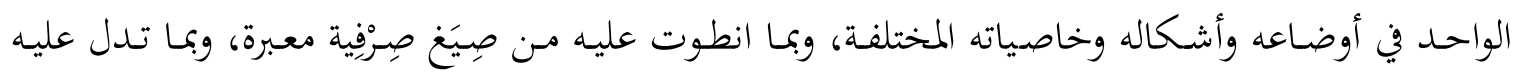


أوضاعُها التركيبية من دلالات، وبما يوفره جرُمُ ألفاظها من تماثلات صوتية تساعد في إبهاج السامع وإيقاظ

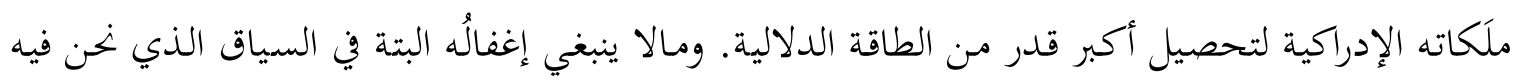

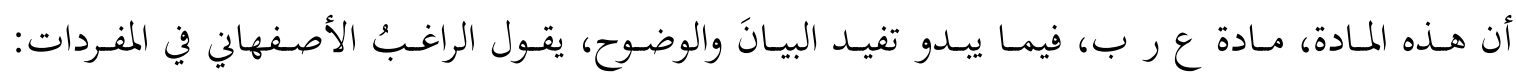

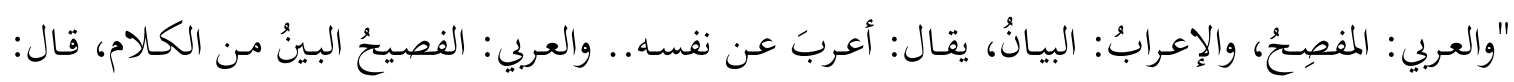

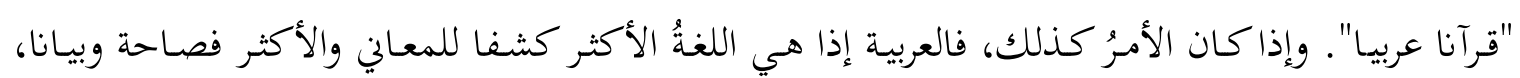

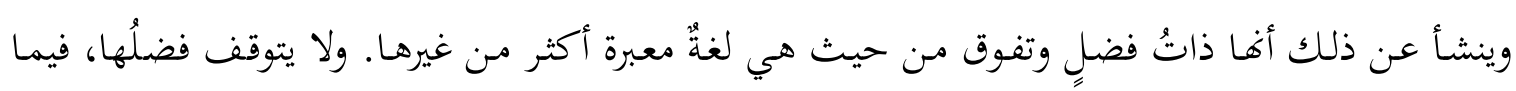

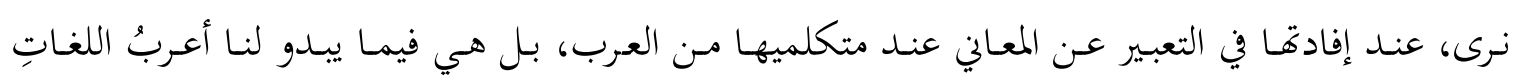

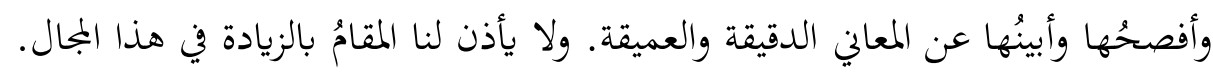

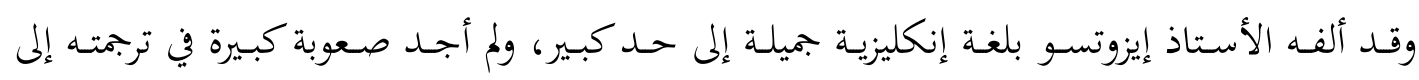

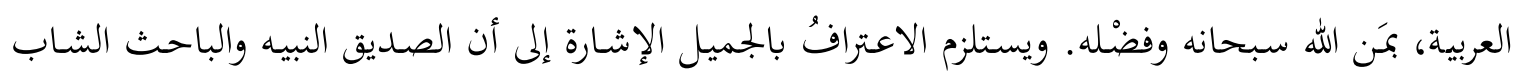

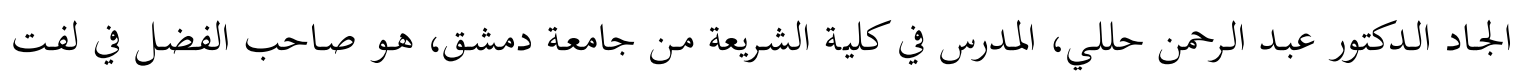

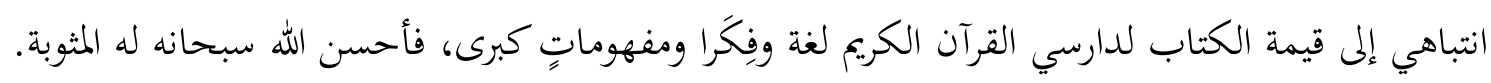

